\title{
Honduras: ConTINUIDAD EN LA AGENDA DE GOBIERNO EN UN NUEVO CONTEXTO PARTIDISTA*
}

\author{
Honduras: Continuity in the Government's Agenda in a New Partisan \\ Context
}

\section{PATRICIA OTERO FELIPE}

Universidad de Burgos

\section{JUAN ANTONIO RODRÍGUEZ ZEPEDA}

Universidad de Salamanca

\begin{abstract}
RESUMEN
Este texto analiza los principales hechos políticos, económicos y sociales acaecidos en Honduras durante el 2015. En la primera parte se realiza una breve valoración de la coyuntura política. Asimismo se analiza el desempeño del país respecto de los principales indicadores socioeconómicos y se discute la conflictividad social observada en este período. A continuación se ofrece un breve análisis de los resultados electorales de 2013 y su efecto en la incipiente transformación del sistema de partidos. De este modo se realiza un balance de las dimensiones de cambio y continuidad en la escena partidista más inmediata. En la tercera parte se realiza un análisis del Poder Ejecutivo, haciendo énfasis en las principales actuaciones llevadas a cabo por el nuevo gobierno del Partido Nacional. Posteriormente se describe la dinámica legislativa en este período y la lógica de relación con el Ejecutivo. El artículo concluye con una valoración general acerca del estado de la democracia en el país y los retos más urgentes que debe enfrentar.
\end{abstract}

Palabras clave: Cambio, continuidad, gobierno nacional, seguridad, sistema de partidos.

\begin{abstract}
This article analyses the main political, economic, and social events that happened in Honduras during 2015. Firstly, we present a brief description of the political situation of the country. Furthermore, we discuss Honduras main socioeconomic indicators and the social turmoil that was prevalent during the past year. Next, we provide an analysis of the 2013 electoral process and its effect on the transformation of the electoral system. At this point we make an assessment of the dimensions of change and continuity in the partisan landscape over the near future. In the third section we carry out an analysis of the Honduran executive branch, emphasizing the main policies enacted by the new government headed by the National Party. Next we discuss the legislative dynamic during this period and the relationship between Congress and the President. We conclude by describing the general state of democracy in this country and the more pressing challenges that it faces.
\end{abstract}

Key words: Change, continuity, national government, security, party system. 


\section{TEMAS DESTACADOS EN LA REALIDAD NACIONAL EN 2015}

Honduras inició 2015 haciendo frente a los problemas endémicos de tipo social y económico que sufre desde hace décadas, algunos de ellos agudizados, pero en un contexto político diferente. El nuevo escenario partidista nacido de las elecciones de finales de 2013 ha puesto de manifiesto la debilidad del histórico bipartidismo y ha marcado una nueva etapa política. Unos resultados que han condicionado una dinámica parlamentaria diferente que en la práctica, como se muestra más adelante, no ha impedido que el ejecutivo del Partido Nacional de Honduras (PNH) haya sacado adelante su agenda de gobierno.

La coyuntura política en estos meses estuvo marcada por los escándalos de corrupción, algunos de estos afectaron de lleno al partido gobernante. Tal vez el más relevante de todos es el escándalo que salió a la luz en mayo de 2015 que desveló el desfalco de más de 350 millones de dólares al Instituto Hondureño de Seguridad Social (IHSS) entre los años 2010 y 2014. En esos años funcionarios y empresarios habrían desviado fondos a empresas fantasmas con las que el PNH habría financiado las campañas de las elecciones internas de 2012 y las generales de 2013. Este hecho derivó en tres meses de protestas ciudadanas, organizadas por la "oposición indignada" y conocidas como "las antorchas", que pidieron la renuncia del presidente Hernández y la creación de una comisión internacional contra la impunidad en Honduras (CICIH). Estas protestas ciudadanas estuvieron alejadas de lineamientos partidarios y tuvieron un origen espontáneo, pero carecieron de red organizativa y liderazgo. Ante estos hechos el Presidente declaró que el Partido Nacional había recibido dinero pero negaba cualquier responsabilidad en estos hechos. ${ }^{1}$ La respuesta del gobierno fue la propuesta de creación de la Misión de Apoyo contra la Corrupción y la Impunidad en Honduras (MACCIH), que fue respaldada por la OEA y la UE que fue instalada en febrero de $2016 .^{2}$

No fue este el único escándalo, aunque sí el de mayor repercusión mediática. Otros hechos acaecidos en los últimos meses dan cuenta de la magnitud de la corrupción política en el país y evidencian su peligrosa combinación con el tráfico de narcóticos y el crimen organizado. Por ejemplo, la detención de Fabio Lobo, hijo del expresidente Porfirio Lobo por su supuesta vinculación al narcotráfico, o la detención de Jaime Rosenthal Oliva quien fue, además de un banquero y empresario de renombre en el país, una figura clave en el liberalismo y que fue acusado junto con su hijo Yani y sobrino Yankel Antonio de proveer servicios de lavado de dinero a grupos vinculados al narcotráfico por la Oficina

1 En este escándalo hay relevantes figuras nacionalistas implicadas, como la vicepresidenta del Congreso Lena Gutiérrez vinculada a una de las empresas que vendió equipos al IHSS con sobrecostes, o Roberto Cardona, exviceministro de la Secretaría de Agricultura y Ganadería y exviceministro de la Secretaría de Recursos Naturales, a quien se le atribuyó haber recibido pagos de hasta 150.000 dólares por parte de empresarios implicados para que no fueran acusados ante el Ministerio Público. “Honduras: Alto ejecutivo ayudó al MP a desenredar madeja de pagos", El Heraldo, 11-8-2015. Asimismo, al director del Instituto Nacional de Estadística Ramón Espinoza se le acusó de haber desviado fondos del IHSS para la campaña política del Partido Nacional en las elecciones generales de 2013. "Testigo clave revela cómo se drenaron los fondos del INE para campaña de $\mathrm{JOH}^{\prime \prime}$, Criterio, 1-12- 2015.

2 "Partido Nacional financió campaña electoral con dinero ligado al fraude al sistema de seguridad social", $\mathrm{La}$ Prensa, 5-6-2015. 
de Control de Activos Extranjeros del Departamento del Tesoro de los Estados Unidos (OFAC) (Moreno, 2015).

En general, el 2015 ha sido un año de gran movilización y conflictividad social, especialmente entre mayo y septiembre, teniendo como punto en común la protesta contra la corrupción y la impunidad en el país que, a pesar de la mejora en el Índice de Percepción de la Corrupción en 2015, sigue colocando a Honduras como uno de los países más corruptos de la región. ${ }^{3}$ Según las estadísticas publicadas por CESPAD, ${ }^{4}$ las protestas más numerosas fueron las relacionadas con los escándalos de corrupción (186), seguidas de las demandas de derechos humanos (123), y aquellas de carácter económico, relacionadas con mejoras salariales de empleados públicos o los despidos de la Empresa Nacional de Energía Eléctrica, del Servicio Nacional de Acueductos y Alcantarillados. Otras tuvieron que ver con el cierre de empresas del Grupo Continental (116), o con diferentes reivindicaciones sociales (87), así como las relacionadas con reclamos por la tierra y los recursos naturales, la lucha de los pueblos originarios y las comunidades rurales contra las concesiones de Recursos Naturales y la política extractivista del Estado (31).

Otro de los temas destacados a lo largo del 2015 se refiere a la persistencia del problema de violencia y las acciones llevadas a cabo desde el gobierno para combatirla. Como ha sido destacado, Honduras vivió una escalada de criminalidad sin precedentes desde principios de los 2000, donde la tasa de homicidios pasó de 51 casos por cada 100 mil habitantes a 85 en el año 2012, unas cifras que lo situaron como uno de los países más violentos del mundo. Una violencia criminal de carácter "local" que se une a la vinculada al crimen organizado por el tráfico de drogas y a la ejercida por las maras. Según los datos del Observatorio de la Violencia de la Universidad Nacional Autónoma de Honduras, en 2013 se cometieron 109 masacres y 6.757 homicidios, lo que representó un promedio mensual de 563 homicidios y un promedio diario de 19 homicidios. Desde entonces estas cifras han comenzado a reducirse de manera significativa. Los últimos datos publicados por el Observatorio de la Violencia del Instituto Universitario en Democracia, Paz y Seguridad (2016) presentan para el 2014 una tasa de 68,0 homicidios por cada 100.000 habitantes, que disminuye a 60,0 en 2015. Unas cifras que siguen siendo extraordinariamente altas en el contexto regional, y que han motivado por parte de las últimas administraciones diferentes respuestas en forma de política de seguridad, como se detalla más adelante.

En términos económicos, durante los dos primeros años de la presidencia de Juan Orlando Hernández Honduras ha mostrado una tendencia positiva en algunos indicadores macroeconómicos. En 2014 el PIB creció 3,1\%, mientras que la estimación para el año 2015 fue de un crecimiento alrededor del 3\%. También se observó un control de la inflación,

3 El país pasó de ocupar el lugar 126, en 2014 (de 175 países), a 112 en 2015 (168 países). El gobierno actual firmó un Convenio con Transparencia Internacional en septiembre de 2014 con el fin de fijar compromisos en la lucha contra la corrupción y la rendición de cuentas y que permite al organismo a realizar procesos de investigación en las diferentes instituciones.

4 CESPAD (2015a). 
la que pasó de 5,6\% en 2014 a un crecimiento del IPC de 2,4\% en el año anterior. Por su parte, el déficit público se redujo de 7,6\% en 2013 a 4,7\% en 2014 y se estima que será del 3,5\% en 2016. Sin embargo, a pesar de la leve mejoría mostrada por el país durante estos años, hay algunos factores que hacen que la situación económica hondureña siga siendo delicada. En primer lugar, porque el golpe de Estado de 2009 detuvo la inercia de mejora de calidad de vida de las personas menos favorecidas. ${ }^{5}$ A partir de 2010, la proporción del ingreso nacional que representan las personas más pobres de Honduras se ha contraído consistentemente. Además, el gasto público en educación y salud, como porcentaje del PIB, también se ha reducido desde ese año (Johnston y Lefebvre, 2013).

Finalmente, hay que destacar la firma del pacto con el FMI para recibir un crédito de 189 millones de dólares durante tres años a partir de 2015. Dicho acuerdo obliga al gobierno hondureño a aplicar medidas de austeridad económica que, debido a su muy alta proporción de personas en situación de pobreza (62\% de la población), pueden agravar la brecha entre ricos y pobres. La desigualdad de ingreso en el país sigue siendo una de las más altas de América Latina, con un coeficiente GINI de 53,7 (2013) y donde el 20\% peor remunerado representa solo el 3,1\% del ingreso nacional (2013) -unas cifras que no parecen mejorar sustancialmente con la aplicación de los programas sociales impulsados desde el gobierno-. Así, el problema del pacto con el FMI es que pone énfasis en los recortes de gasto público, pero no en el aumento de la recaudación fiscal. Durante 2014 y 2015 la inversión en capital por parte del gobierno, la que corresponde al gasto en infraestructura, disminuyó a 4,8\% y 3,7\% del PIB, respectivamente. Al reducirse dicha inversión, los hondureños tendrán menos oportunidades de abatir el desempleo y subempleo que alcanzaron al 3,9\% y 11,7\% de la población económicamente activa en 2013, y donde el 40,8\% de las personas que trabajaron 36 horas o más en una semana no ganaron el salario mínimo (Lefebvre, 2015).

\section{UNA NUEVA ETAPA PARA EL SISTEMA DE PARTIDOS}

A pesar de las continuidades manifiestas en términos sociales y económicos, es en el ámbito partidista donde encontramos importantes novedades, como han puesto de manifiesto los procesos electorales de 2013, que rompen con la tónica de estabilidad característica del sistema político hondureño (Ajenjo, 2007). Se trata de una estabilidad muy dependiente de la fortaleza de sus dos principales partidos, el Partido Nacional (PNH) y el Partido Liberal (PLN), que se han alternado en el poder desde hace décadas, sin que terceros partidos hayan amenazado su protagonismo. Hasta ahora los patrones en la competencia partidista habían sido bastante predecibles: una reducida volatilidad, bajos niveles de competitividad presidencial y parlamentaria, una concentración del

5 De acuerdo con Johnston y Lefebvre (2013), el coeficiente Gini descendió 3,6\% anual en promedio entre 2006 y 2008 , mientras que aumentó 5,9\% en los dos años posteriores al golpe de Estado. Entre otras medidas, el aumento del salario mínimo en $60 \%$ durante la presidencia de Zelaya contribuyó a la mejoría en la distribución del ingreso en Honduras. Asimismo, la pobreza extrema y la pobreza disminuyeron en 20,9\% y 7,7\% durante el gobierno de Zelaya, y aumentaron 26,3\% y 13,2\% entre 2010 y 2012. 
voto próxima al 90\%, y un número efectivo de partidos cercano a dos; indicadores que revelaban un bipartidismo consolidado y podríamos decir con visos de mantenerse si no fuera por los hechos acaecidos en 2009 (Tabla 1).

Tabla 1. Evolución de la oferta partidista 1980-20136

\begin{tabular}{lrrrrrrrrrr}
\hline & 1980 & 1981 & 1985 & 1989 & 1993 & 1997 & 2001 & 2005 & 2009 & 2013 \\
\hline Concentración pres. & - & 95,54 & 96,5 & 96,61 & 95,98 & 95,42 & 96,47 & 96,12 & 94,68 & 65,67 \\
Concentración leg & 95,83 & 95,54 & 96,5 & 96,61 & 95,98 & 91,11 & 87,29 & 85,86 & 87,2 & 61,15 \\
Fragmentación elect. & 0,53 & 0,54 & 0,53 & 0,53 & 0,53 & 0,58 & 0,61 & 0,62 & 0,59 & 0,76 \\
Fragmentación leg. & 0,54 & 0,54 & 0,53 & 0,51 & 0,51 & 0,54 & 0,59 & 0,58 & 0,57 & 0,72 \\
NEPE & 2,16 & 2,17 & 2,14 & 2,13 & 2,14 & 2,37 & 2,59 & 2,65 & 2,46 & 4,14 \\
NEPP & 2,11 & 2,15 & 2,12 & 2,03 & 2,03 & 2,18 & 2,42 & 2,37 & 2,3 & 3,58 \\
\hline
\end{tabular}

Fuente: Elaboración propia a partir de los datos proporcionados por el TSE.

El golpe de Estado tuvo grandes consecuencias para el país y dejó su huella también en el sistema de partidos. Por un lado, por los efectos en los partidos existentes, en particular para el PLH que no solo perdió las elecciones de ese año, sino que quedó internamente fracturado, sufriendo además importantes deserciones que acabaron en el Frente Nacional de Resistencia Popular (FNRP); en tanto que el PNH capitalizó electoralmente parte del descontento. Pero el impacto más importante fue el incremento de la oferta partidista, con la incorporación al sistema de dos exitosos partidos: Libertad y Refundación (LIBRE) y el Partido Anticorrupción (PAC). ${ }^{7}$ Con LIBRE irrumpió la izquierda política en un país donde había tenido una presencia casi testimonial y cuyas posibilidades de influencia en la dinámica política habían sido escasas. Surgido como brazo político del FNRP, presenta dos características esenciales: primero, la diversidad interna de la organización, donde se incluyeron desde su inicio elementos partidistas, sociales y gremiales, aunque con un mayor predomino de exliberales, que tomaron forma de cinco movimientos internos

6 El índice de concentración nos permite ver en qué medida los electores distribuyen sus preferencias entre un número elevado o reducido de formaciones políticas. Se ha hallado a partir de la suma de los votos conseguidos por el primer y segundo partidos. El índice de fragmentación de Rae (1967) muestra en qué medida el poder político por medio de los partidos está más o menos concentrado en diferentes fuerzas políticas. Se interpreta como la probabilidad de que dos electores hayan votado a dos partidos distintos (versión electoral), o que al elegir dos representantes, pertenezcan a grupos distintos (versión parlamentaria). Por su parte el Número Efectivo de Partidos (NEP) diseñado por Laakso y Taagapera (1979) indica el número de agrupaciones que obtienen una proporción importante de votos o escaños. Se interpreta como el número de partidos relevantes que compiten electoralmente (NEPE) o existen en el Congreso (NEPP), considerando su tamaño relativo (Ruiz y Otero, 2013).

7 Además de estos, surgieron en 2012 el FAPER y la Alianza. El Frente Amplio Político Electoral en Resistencia (FAPER), ubicado en la izquierda, se conformó por organizaciones populares y exmilitantes de PUD y PLH. La Alianza Patriótica Hondureña fue un partido creado por el general retirado Romeo Vásquez, quien fuera jefe de las FF.AA. en tiempos de Zelaya. Estaba compuesto por otros exgenerales retirados y reservistas de las FF.AA.; se ubicaría en el extremo derecho del espectro ideológico y buscó sus apoyos en los ciudadanos críticos con la gestión de Lobo y con los partidos tradicionales. 
en las primarias de 2012; segundo, su amplia cobertura nacional y social heredada tanto del Frente como del Partido Liberal, así como su vinculación con sindicatos del sector público, campesinos y estudiantes, lo que le permitió posicionarse como actor político relevante, movilizando dichos sectores (Otero Felipe, 2013). Por su parte, el PAC, creado por Salvador Nasralla, un popular periodista deportivo, articuló desde sus inicios un discurso centrado en la lucha contra la corrupción y la regeneración de la institucionalidad del país y logró establecer una buena estructura territorial en pocos meses en los centros urbanos.

Los resultados de las elecciones de noviembre de 2013 confirmaron que asistimos a un nuevo ciclo político. En primer lugar se rompe la estabilidad de los apoyos electorales a los dos partidos mayoritarios. El Partido Nacional revalidó su triunfo y por primera vez logró ganar dos comicios seguidos (Tabla 2). Juan Orlando Hernández, que ya había tenido un holgado triunfo en las primarias de 2012, obtuvo en las presidenciales $37 \%$ de los votos, una victoria satisfactoria dadas las circunstancias pero ajustada si la comparamos con los resultados de los últimos años. El PLH con Mauricio Villeda obtuvo el peor resultado de su historia, siendo relegado al tercer lugar, lo que evidenció la incapacidad del partido en retener a sus bases. Por su parte, el partido LIBRE, con Xiomara Castro, fue el segundo más votado logrando casi un millón de votos, consiguiendo atraer no solo votos de liberales descontentos con el partido tras el golpe, sino también de aquellos hondureños que deseaban un cambio político. Mientras que el candidato del PAC, Salvador Nasrralla, quedó en cuarto lugar.

En segundo lugar se modificó el patrón de apoyo electoral a nivel departamental: mientras que el PNH se afianzó en casi todo el país siendo primera fuerza en trece de los dieciocho departamentos, el PLH fue el más votado tan solo en uno (Islas de la Bahía). LIBRE desplazó a los liberales en buena parte del país, siendo el más votado en Olancho, Colón y Gracias a Dios y fue la segunda fuerza en once departamentos. Acusando una menor estructura territorial, el PAC obtuvo buenos resultados en los dos departamentos más urbanos, especialmente en Cortés, donde Nasralla fue el candidato con más apoyos, y en Francisco Morazán. El tercer elemento de cambio en estos comicios es el perfil de los candidatos presidenciales. Frente a los empresarios o terratenientes con una dilatada trayectoria política en los partidos y por tanto conocidos por los ciudadanos, con los nuevos competidores entran en la escena política candidatos ajenos a la política tradicional: Xiomara Castro, exprimera dama con escasa actividad política previa que alcanzó gran popularidad desde la expulsión de Zelaya; Salvador Nasralla, reconocido periodista deportivo; Vázquez, exjefe de las FF.AA. y Andrés Pavón, activista de los derechos humanos.

Los resultados en el Congreso también mostraron un escenario novedoso. El PNH ganó el primer lugar con el 33\% de los votos, en tanto que los partidos LIBRE, PAC y el Partido Liberal sumaron juntos más del $60 \%$ de los votos. En virtud de los resultados en escaños, ningún partido obtuvo la mayoría absoluta. LIBRE fue el segundo partido más votado, logrando 37 escaños y el PLH quedó relegado al tercer lugar, con tan solo 27 diputados. El PAC entró en el Congreso con 13 representantes, mientras que los tres 
Tabla 2. Resultados de las elecciones de 2013

\begin{tabular}{|c|c|c|c|c|c|c|c|}
\hline \multirow{2}{*}{$\begin{array}{l}\text { Partido y candidato } \\
\text { presidencial }\end{array}$} & \multicolumn{2}{|c|}{$\begin{array}{l}\text { Elección } \\
\text { presidencial }\end{array}$} & \multicolumn{3}{|c|}{$\begin{array}{l}\text { Elección } \\
\text { legislativa }\end{array}$} & \multirow{2}{*}{$\frac{\text { Parlacen }}{\text { Escaños }}$} & \multirow{2}{*}{$\begin{array}{c}\begin{array}{c}\text { Elección } \\
\text { municipa }\end{array} \\
\text { Alcaldías }\end{array}$} \\
\hline & Votos & $\% *$ & Votos & $\%$ & Escaños & & \\
\hline $\begin{array}{l}\text { Partido Nacional, Juan } \\
\text { Orlando Hernández }\end{array}$ & 1.149 .302 & 36,89 & 9.255 .904 & 33,64 & 48 & 6 & 183 \\
\hline LIBRE, Xiomara Castro & 896.498 & 28,78 & 7.568 .392 & 27,51 & 37 & 5 & 31 \\
\hline $\begin{array}{l}\text { Partido Liberal, Mauricio } \\
\text { Villeda }\end{array}$ & 632.320 & 20,30 & 4.670 .157 & 16,97 & 27 & 3 & 83 \\
\hline PAC, Salvador Nasralla & 418.443 & 13,43 & 4.169 .245 & 15,15 & 13 & 1 & 0 \\
\hline PDC, Orle Solís & 5.194 & 0,17 & 444.734 & 1,62 & 1 & 1 & 1 \\
\hline $\begin{array}{l}\text { Alianza Patriótica, Romeo } \\
\text { Vásquez }\end{array}$ & 6.105 & 0,20 & 272.398 & 0,99 & 0 & 1 & 0 \\
\hline PINU, Jorge Aguilar & 4.468 & 0,14 & 504.684 & 1,83 & 1 & 1 & 0 \\
\hline \multirow{2}{*}{ FAPER, Andrés Pavón-PUD } & \multirow{2}{*}{3.118} & \multirow{2}{*}{0,10} & 128.488 & 0,47 & 0 & 1 & \multirow{2}{*}{0} \\
\hline & & & 469.825 & 1,71 & 1 & 1 & \\
\hline Independientes & - & - & 28.971 & 0,11 & 0 & & 0 \\
\hline Votos válidos & 3.115 .448 & 95,12 & & & & & \\
\hline Votos nulos & 108.171 & 3,30 & & & & & \\
\hline Votos en blanco & 51.727 & 1,58 & & & & & \\
\hline Total & 3.275 .346 & 100 & 27.512 .798 & 100 & 128 & 20 & 298 \\
\hline Participación electoral & & 61,16 & & & & & \\
\hline
\end{tabular}

*Porcentaje de voto sobre voto válido. PUD y FAPER se presentaron en coalición en tres departamentos para las elecciones legislativas (Copán, Gracias a Dios e Intibucá). Fuente: La Gaceta, República de Honduras y Declaratoria Final del Tribunal Supremo Electoral.

partidos minoritarios, PDCH, PINU-SD y PUD, lograron uno cada uno lo que evitó su disolución. FAPER y ALIANZA no alcanzaron el 2\% de los votos a nivel presidencial ni obtuvieron diputados, por lo que el Tribunal Supremo Electoral (TSE) canceló en 2014 su inscripción y personalidad jurídica siguiendo la normativa electoral ${ }^{8}$. Con esta elección se incrementó el número de mujeres diputadas hasta 33 , lo que supone el $26 \%$, muy lejos del objetivo legal marcado del $40 \% .{ }^{9}$ La presencia de nuevos partidos también favoreció una tasa de renovación más alta, así solo 48 diputados fueron reelectos (el 37,5\% frente al 39,4\% en 2009), de estos 29 pertenecientes al PNH, 14 al PLH, 1 del PUD y 1 de la Democracia Cristiana, y dos de LIBRE (exliberales). Esto ha modificado el perfil social

8 Recientemente la sala de lo Constitucional de la Corte Suprema de Justicia ha revisado esta decisión "Autorizan a FAPER y Alianza Patriótica regresar a la política", La Prensa 13-1-2016.

9 Desde la reforma de la Ley Electoral y de Organizaciones Políticas del 2012, era obligatoria una cuota de género del $40 \%$ para todos los partidos que realizaron elecciones internas y primarias, mientras que los partidos que no realizaron estos procesos debían cumplir con la cuota al elaborar las planillas. Sin embargo, ningún partido cumplió con este requerimiento. 
y profesional de los diputados, contando ahora con un mayor número de profesionales sin experiencia política previa.

Fueron unas elecciones muy vigiladas desde el punto de vista nacional e internacional, pero a pesar de todo y como viene siendo habitual, poco transparentes y con numerosas irregularidades, antes, a lo largo de la campaña electoral y durante la votación: ausencia de transparencia en los fondos utilizados por partidos y candidatos bajo la sospecha de dinero ilícito proveniente del crimen organizado, el diferente acceso a los medios de comunicación entre partidos grandes y pequeños, el uso de publicidad institucional del $\mathrm{PNH}$, la alteración de las actas de la mesas receptoras y el tráfico de las credenciales de los representantes de los partidos (Otero Felipe, 2014). Además, hay que señalar varios episodios de violencia e intimidación contra candidatos y activistas (Spring, 2013) ${ }^{10} \mathrm{o}$ las anomalías durante el proceso de votación, entre ellas la compra de votos que llevaron a los candidatos de LIBRE y PAC a impugnar los resultados.

El estable comportamiento electoral hondureño ha tenido su reflejo en los bajos niveles de volatilidad electoral agregada, sin embargo, la entrada de nuevas fuerzas políticas en estos comicios ha incrementado estos niveles de volatilidad presidencial y legislativas (Gráfico 1). Se confirma así que el "voto duro" de los partidos ya no es suficiente y que la atracción del voto independiente y urbano, mayoritariamente joven, es fundamental para la victoria electoral. Otro elemento destacado en estas elecciones fue la mayor participación electoral comparada con las citas electorales anteriores, en las que se advertía un aumento progresivo de la abstención (Gráfico 2). Este porcentaje en la década de los noventa no era mayor que los votos que alcanzaban los partidos mayoritarios, sin embargo, desde el 2001 y hasta 2013 los dos partidos más votados no igualaban el porcentaje de ausentes. Un abstencionismo que se ha explicado por diferentes factores: el paulatino desencanto partidista, la desconfianza hacia las instituciones, el funcionamiento endogámico de los partidos, o la escasa diferenciación entre los dos partidos tradicionales en su desempeño en los gobiernos. No obstante, los problemas para mantener un censo electoral actualizado hacen sospechar que las cifras reales de participación electoral sean más altas.

La llegada de ambas fuerzas políticas ha supuesto asimismo una novedad también en términos de diferenciación ideológica y polarización del sistema de partidos que fue tradicionalmente muy baja y que en la actualidad se ha incrementado sustancialmente (Tabla 3). PLH y PNH se alternaron en el poder mostrando con su gestión en el gobierno que cada vez se parecían más ideológica y programáticamente (Ajenjo, 2007). Es más, los últimos años evidenciaron mayores diferencias entre las facciones de los partidos y particularmente entre los candidatos que entre ambos partidos, mostrando un PLH cada vez más a la derecha con candidatos más cerca del PNH (Otero Felipe, 2013).

10 A lo largo de la campaña fueron asesinados tres candidatos a alcalde, dos a regidor, uno a diputado, además de un alcalde, dos vicealcaldes y dos regidores en el cargo. A estas cifras habría que sumar los diez candidatos asesinados en el proceso de primarias del 2012. 
Gráfico 1. Volatilidad electoral agregada

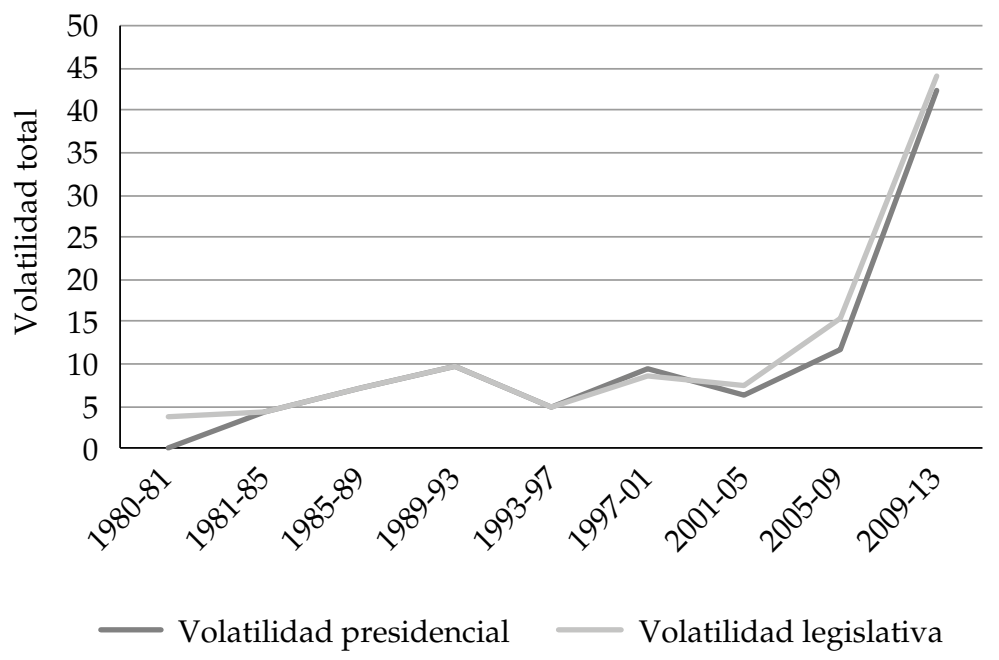

Fuente: Elaboración propia.

Gráfico 2. Abstención sobre el censo electoral y voto presidencial

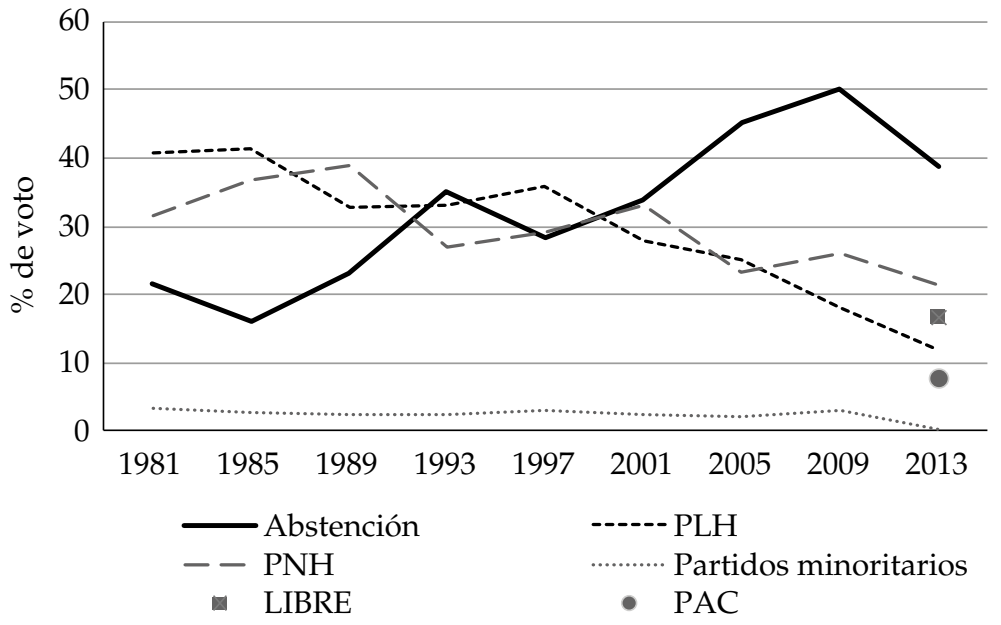

Fuente: Elaboración propia.

Todos estos elementos muestran un bipartidismo en proceso de transformación y una nueva etapa en el sistema de partidos. ${ }^{11}$ Sin embargo, hay dos señas de identidad del

11 La lógica bipartidista se mantuvo únicamente en las elecciones locales donde PNH y PLH mantuvieron gran parte de las alcaldías. Así, el PNH sigue manteniendo Tegucigalpa, convertido en un feudo nacionalista, pero ganó de forma muy ajustada en San Pedro Sula. 
sistema que han reforzado su estabilidad y han mantenido la hegemonía de los dos partidos tradicionales. Un aspecto es el clientelismo como mecanismo para mantener las lealtades partidistas, a lo que no es ajena una estructura territorial forjada durante décadas y muy bien organizada. Esto también ha significado el acceso privilegiado a los recursos estatales como partidos en el gobierno y al manejo partidista de las instituciones, donde se han respetado las "cuotas de poder". En segundo lugar, el faccionalismo y la estructura vertical de ambos partidos, que ha permitido la incorporación de diferentes sectores y corrientes diversas bajo la misma etiqueta (Ajenjo, 2001). En este sentido, las opciones de los nuevos partidos para mantener su influencia dependerán de su capacidad para apuntalar una base social y lograr una estructura en todo el territorio. Estas circunstancias pueden limitar el éxito de las nuevas formaciones políticas y frenar en el corto plazo cambios más profundos en el sistema.

Tabla 3. Nivel de polarización ideológica ponderada 1994-201812

\begin{tabular}{lcccccc}
\hline $\begin{array}{l}\text { Legislatura (año del trabajo } \\
\text { de campo) }\end{array}$ & $\begin{array}{c}1993-1998 \\
(1994)\end{array}$ & $\begin{array}{c}1998-2002 \\
(1998)\end{array}$ & $\begin{array}{c}2002-2006 \\
(2002)\end{array}$ & $\begin{array}{c}2006-2010 \\
(2006)\end{array}$ & $\begin{array}{c}2010-2014 \\
(2010)\end{array}$ & $\begin{array}{c}\text { 2014-2018 } \\
(2014)\end{array}$ \\
\hline $\begin{array}{l}\text { Polarización ponderada } \\
\text { (autoubicación) }\end{array}$ & 0,22 & 0,53 & 1,98 & 1,42 & 0,74 & 3,05 \\
$\begin{array}{l}\text { Polarización ponderada } \\
\text { (otros partidos) }\end{array}$ & 3,43 & 1,71 & 2,18 & 3,65 & 1,79 & 7,03 \\
\hline
\end{tabular}

Fuente: Elaboración propia a partir de PELA.

\section{NUEVO GOBIERNO NACIONAL, MISMA AGENDA POLÍTICA}

Juan Orlando Hernández tomó posesión de su cargo el 27 de enero de 2014 tras una victoria electoral menos contundente que su predecesor Porfirio Lobo, pero lo hizo en condiciones mucho más favorables que aquel. Como se recordará, Lobo se vio forzado a conformar un gabinete de "integración nacional" tras el golpe de Estado incluyendo figuras de diferentes partidos políticos (PLH, PUD, PDC y PINU), lo que condicionó mucho su acción en el gobierno y ocasionó numerosas críticas desde su propio partido.

El nuevo gobierno mostró desde sus inicios pocas novedades y grandes dosis de continuidad, al incluir varios funcionarios que sirvieron en las administraciones de Lobo y Maduro e incluir personas provenientes de diferentes corrientes del partido, entre ellas

12 Con este indicador se miden las distancias existentes entre los partidos con ideologías más diferentes entre sí o más extremas. Se ofrece el cálculo de la polarización ponderada por el peso en escaños de cada partido, considerando las posiciones ideológicas de los partidos extraídas del proyecto PELA(Universidad de Salamanca). Por un lado se presenta la polarización teniendo en cuenta la autoubicación ideológica de los diputados, y por otro la polarización a partir de la ubicación ideológica que los diputados realizan de los partidos (a excepción del suyo). En ambas se usa la escala de 1 izquierda a 10 derecha, tomando la fórmula de Taylor y Herman (1971). Cuanto más alto sea el valor, mayor será la distancia entre los partidos que componen el sistema y viceversa. 
algunos de los antiguos contendientes de las elecciones internas del 2012, como Ricardo Álvarez, junto con nuevas figuras cercanas a la corriente de Hernández. El Presidente ha modificado su gabinete en forma significativa en dos ocasiones durante su mandato, la primera vez fue a principios del 2015 y la segunda en enero de 2016. A pesar de estos cambios, el perfil del mismo no ha variado sustancialmente. La mayoría son políticos con amplia experiencia en la función pública y que provienen del Partido Nacional. Tal es el caso de Reinaldo Sánchez, actual Secretario de la Presidencia, quien fue ministro Secretario Privado de Lobo. Asimismo, el actual Secretario de Defensa, Samuel Reyes, fue designado presidencial en el período anterior. Por su parte, Wilfredo Cerrato (Secretario de Finanzas) y Marlon Escoto (Secretario de Educación) ostentan sus cargos desde 2012 cuando era presidente Lobo. ${ }^{13}$ También destaca la figura de Jorge Ramón Hernández como coordinador general del gabinete, que fue exsecretario de Gobernación durante la administración de Maduro.

No obstante lo anterior, se puede destacar la presencia de políticos que no militan en el Partido Nacional y que ostentan altos cargos en el gabinete. Dentro de este grupo se pueden encontrar dos políticos del Partido Demócrata Cristiano: Arturo Corrales, Secretario de Relaciones Exteriores y Cooperación Internacional, y Felicito Ávila, quien es Secretario de Trabajo y Seguridad Social. Por otro lado existen secretarios cuya actividad profesional se ha centrado en la iniciativa privada o en asociaciones empresariales. Algunos ejemplos de este perfil son Arnaldo Castillo, Secretario de Desarrollo Económico, cuya trayectoria se ha desarrollado principalmente en empresas relacionadas con el comercio en Asia. Otro ejemplo es Jacobo Paz, Secretario de Agricultura y Ganadería, quien fue presidente de la Asociación Nacional de Acuicultores de Honduras.

Hasta la fecha se han producido algunos cambios en los principales puestos del gabinete presidencial (Tabla 4). Así las cosas, uno de los principales movimientos ha sido la llegada del general del Ejército, Julián Pacheco, a la Secretaría de Seguridad, un área crucial para el gobierno hondureño debido a los grandes problemas de seguridad pública que enfrenta el país. Por otro lado, en la Secretaría de Derechos Humanos, Justicia, Gobernación y Descentralización la nueva titular interina es la abogada y activista de derechos humanos Karla Cueva.

La gran novedad en la conformación del gobierno ha sido el cambio en la estructuración de su gabinete, porque mientras que antes se contaba con diecisiete ministerios, el actual está conformado por ocho gabinetes sectoriales de los cuales dependen quince Secretarías de Estado, donde tan solo se incluyeron a tres mujeres, así como diferentes entidades públicas y programas de gobierno (Figura 1). A estos quince ministros habría que sumar el coordinador, el ministro de la Presidencia, el Secretario del Consejo de Ministros y los tres designados presidenciales. Esto supone una reducción de funcionarios con rango de ministros y la desaparición de varias secretarías con el fin de aliviar el gasto público, pero también la mayor concentración del poder en unas pocas manos. ${ }^{14}$ 
Tabla 4. Composición del gabinete 2014-2018

\begin{tabular}{|c|c|c|c|c|}
\hline Cargo en el gabinete & Enero de 2014 & Partido & $\begin{array}{l}\text { Cambio en } \\
\text { enero de } 2016\end{array}$ & Partido \\
\hline $\begin{array}{l}\text { Ministro coordinador general } \\
\text { de gobierno con rango de secretario } \\
\text { de Estado }\end{array}$ & $\begin{array}{l}\text { Jorge Ramón } \\
\text { Hernández }\end{array}$ & $\mathrm{PNH}$ & Continúa & \\
\hline Secretario de la Presidencia & Reinaldo Sánchez & $\mathrm{PNH}$ & Continúa & \\
\hline $\begin{array}{l}\text { Secretario de Derechos Humanos, } \\
\text { Justicia, Gobernación y } \\
\text { Descentralización }\end{array}$ & Rigoberto Chang & $\mathrm{PNH}$ & $\begin{array}{l}\text { Karla Cueva } \\
\text { *Interina }\end{array}$ & $\mathrm{PNH}$ \\
\hline $\begin{array}{l}\text { Secretario de Relaciones Exteriores, } \\
\text { y Cooperación Internacional }\end{array}$ & Roberto Ochoa & $\mathrm{Nd}$ & Arturo Corrales & $\mathrm{PDCH}$ \\
\hline $\begin{array}{l}\text { Secretario de Desarrollo e Inclusión } \\
\text { Social }\end{array}$ & Lisandro Rosales & $\mathrm{PNH}$ & $\begin{array}{l}\text { Ricardo } \\
\text { Cardona }\end{array}$ & $\mathrm{PNH}$ \\
\hline Secretario de Desarrollo Económico & Aldén Rivera & $\mathrm{PNH}$ & $\begin{array}{l}\text { Arnaldo } \\
\text { Castillo }\end{array}$ & $\mathrm{Nd}$ \\
\hline $\begin{array}{l}\text { Secretario de Infraestructura y } \\
\text { Servicios Públicos }\end{array}$ & Roberto Ordoñez & $\mathrm{PNH}$ & Continúa & \\
\hline Secretario de Seguridad & Arturo Corrales & $\mathrm{PDCH}$ & Julián Pacheco & $\mathrm{Nd}$ \\
\hline Secretario de Defensa & Samuel Reyes & $\mathrm{PNH}$ & Continúa & \\
\hline Secretaria de Salud & Edna Yolani Batres & $\mathrm{PNH}$ & Continúa & \\
\hline Secretario de Educación & Marlon Oniel Escoto & Libre* & Continúa & \\
\hline $\begin{array}{l}\text { Secretario de Trabajo y Seguridad } \\
\text { Social }\end{array}$ & Carlos Madero & $\mathrm{PNH}$ & Felicito Ávila & $\mathrm{PDCH}$ \\
\hline Secretario de Agricultura y Ganadería & Jorge Lobo & $\mathrm{PNH}$ & Jacobo Paz & $\mathrm{PNH}$ \\
\hline $\begin{array}{l}\text { Secretaría de Recursos Naturales, } \\
\text { Ambiente y Minas }\end{array}$ & $\begin{array}{l}\text { José Antonio } \\
\text { Galdámez }\end{array}$ & $\mathrm{PNH}$ & Continúa & \\
\hline Secretaría de Finanzas & Wilfredo Cerrrato & $\mathrm{PNH}$ & Continúa & \\
\hline Designado Presidencial & Rossana Guevara & $\mathrm{PNH}$ & Continúa & \\
\hline Designado Presidencial & $\begin{array}{l}\text { Ricardo Antonio } \\
\text { Álvarez }\end{array}$ & $\mathrm{PNH}$ & Continúa & \\
\hline Designado Presidencial & $\begin{array}{l}\text { Lorena Enriqueta } \\
\text { Herrera }\end{array}$ & $\mathrm{PNH}$ & Continúa & \\
\hline
\end{tabular}

Fuente: Elaboración propia.

Estos dos años de gobierno de Juan Orlando Hernández han evidenciado un estilo poco inclinado al diálogo, como ya pusiera de manifiesto en la legislatura pasada siendo presidente del Congreso, a pesar de la inicial predisposición a construir pactos y consensos. De hecho, en enero de 2014 se instalaron cinco mesas de diálogo con representantes de sectores campesinos, obreros, empresarios, Iglesias, universidades y sociedad civil, con el fin de estudiar reformas profundas al sistema democrático, entre ellas cuestiones acerca de seguridad, desarrollo social, crecimiento económico, lucha 


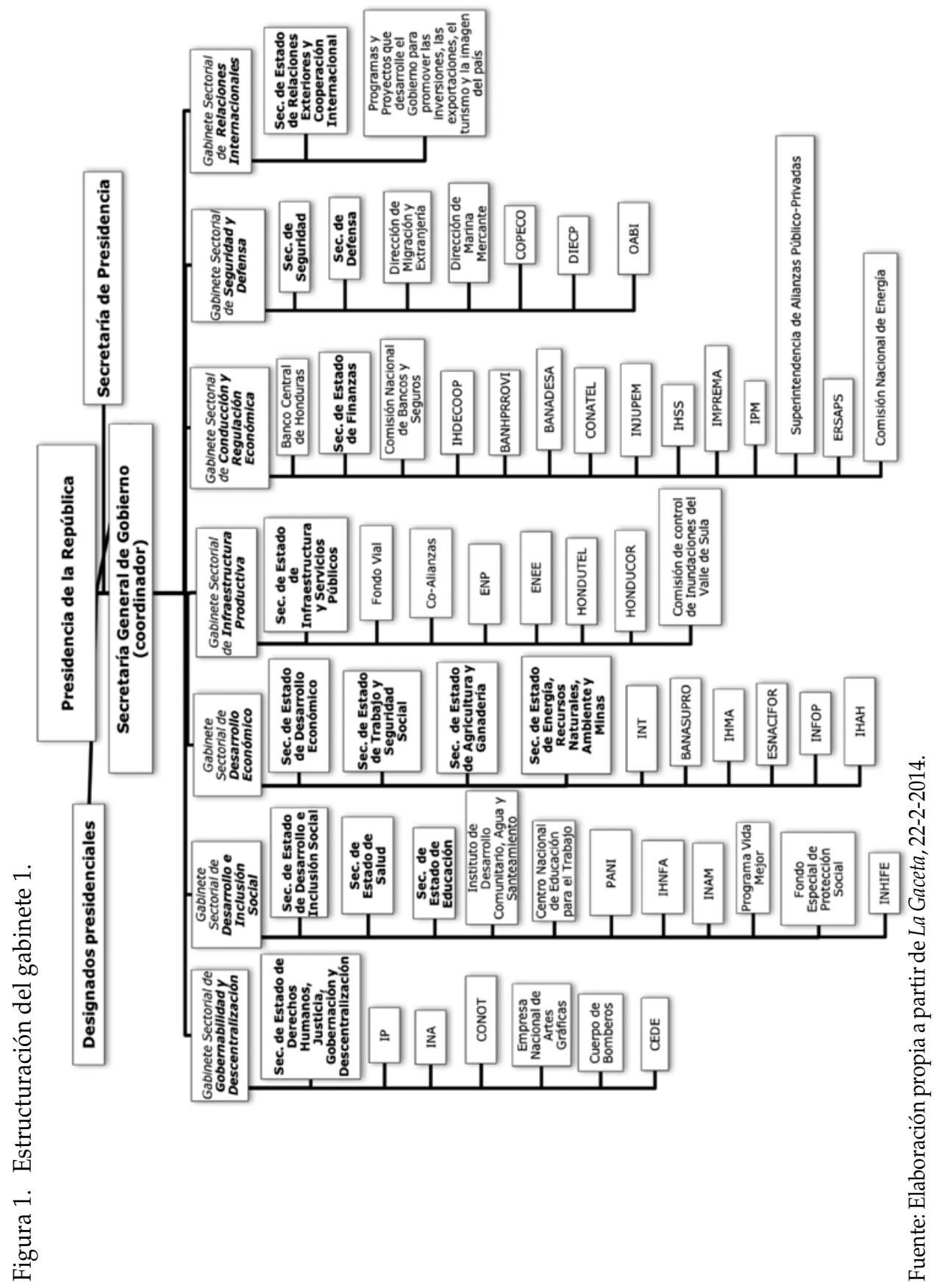


contra la corrupción o modernización del Estado. Pese a su difusión inicial, el llamado "Pacto por Honduras" no se plasmó en ninguna acción concreta por parte del gobierno.

Sin embargo, una de las novedades más relevantes que ha tenido lugar durante su gobierno es el cambio constitucional que supone la derogación del artículo 239 que prohibía referirse o promover la reelección constitucional. En abril de 2015 los cinco magistrados de la sala constitucional de la Corte Suprema de Justicia fallaron a favor de sendos recursos que habían interpuesto el expresidente Callejas y diputados del PNH y del PUD. Estos pedían derogar el artículo 239 que preveía la prohibición de la reelección presidencial, así como el 42.5 que establece la pérdida de ciudadanía por promover o incitar la reelección presidencial. Los diputados solicitaron además derogar el artículo 330 del Código Penal que establece penas de cárcel e inhabilitación para un cargo público por promover desde la Presidencia la reelección. PLH, LIBRE y PAC se manifestaron en contra, emprendiendo los dos primeros acciones legales para revertir el fallo, ${ }^{15}$ de este modo, si estas no prosperan se permitirá la reelección presidencial en los próximos comicios, un cambio de enorme trascendencia.

En cuanto a la agenda política del gobierno de Hernández, se ha caracterizado por la continuidad con la administración anterior. No hay que olvidar que siendo presidente del Congreso de Hernández en los últimos meses al frente del Legislativo impulsó gran parte de la legislación -que ahora como Presidente forma parte de su agenda de gobierno-, facilitando así la estructura institucional y legal necesaria para las políticas públicas puestas en marcha desde el 2014 en diferentes ámbitos. En este sentido, semanas antes de la toma de posesión el Congreso anterior, que contaba con una abrumadora mayoría nacionalista, aprobó numerosos decretos-ley y nuevas leyes de diferente índole que han significado la consolidación de un modelo neoliberal. Entre estas se encuentran las medidas fiscales, como la Ley de Ordenamiento de las Finanzas Públicas, Control de las Exoneraciones y Medidas Antievasión, que incluye, entre otros, el aumento del Impuesto sobre Ventas (ISV) del 12 al 15\% en todos los productos (con la excepción de los incluidos en la canasta básica), más tributos a la telefonía móvil o al precio del combustible, todo ello con el objetivo de reducir el gasto público y aumentar los ingresos. Con estas medidas, consideradas por algunos analistas como regresivas, la administración de Hernández ha podido contar con más recursos. Otra de las políticas puesta en marcha un mes antes de su gobierno fue la aprobación de la Ley Orgánica de las Zonas de Empleo y Desarrollo Económico (ZEDE), anteriormente conocidas como "ciudades modelo" (Sosa, 2014).

No obstante, la política de seguridad y la lucha contra la delincuencia es probablemente el elemento más destacable de los dos años de gobierno nacionalista. Como se señalaba con anterioridad, la seguridad vinculada a la militarización comenzó en las postrimerías de la legislatura anterior. De modo que la política llevada a cabo en el gobierno de

15 "Reelección presidencial: bancada de LIBRE presenta recurso de inconstitucionalidad", Tiempo 7-9-2015,

"Activistas liberales presentan recurso contra histórico fallo", La Tribuna, 25-4-2016. 
Hernández es una mera continuación en concepción y en acciones de las que comenzó siendo presidente del Congreso Nacional.

En 2013 se legisló la normativa relativa al proceso de militarización con la creación de la Policía Militar del Orden Público (PMOP), una unidad militar de más de dos mil miembros a la que se le encomendó la seguridad y el combate al crimen organizado. Una acción que desoyó las recomendaciones realizadas por la Comisión de Reforma a la Seguridad Pública que criticaban la ambigüedad en la amplitud de las funciones de la Policía Militar, pero que también encontró críticas en parte de la ciudadanía, las organizaciones de derechos humanos, y gran parte de los partidos de oposición. ${ }^{16}$ En enero del 2015 se intentó dar un carácter constitucional al someter el decreto sobre el rango constitucional de la $\mathrm{PMOP}$, sin embargo fue rechazada por 67 votos en contra (36 de LIBRE, 13 de PAC, 1 de PINU-SD y 17 del PLH) frente a 61 a favor (con los 48 del PNH, 2 del PDCH,17 1 de PUD, y 10 del PLH). De este modo, las reformas de los artículos 274 y 239 de la Constitución, que se realizaron en agosto de 2013, quedaron sin efecto. ${ }^{18}$ Hay que señalar, además, que esta policía militarizada ha sido reforzada desde el punto de vista presupuestario, al contar con un presupuesto especial además de una asignación que proviene de los fondos de la llamada "Tasa de Seguridad" puesta en marcha en 2011. ${ }^{19}$

Otras medidas relevantes de esos últimos meses del gobierno de Lobo, que allanaron el camino al nuevo gobierno nacionalista, fueron la extradición a Estados Unidos de los narcotraficantes, un decreto para depurar la Policía Nacional, muy desprestigiada por la vinculación con el narcotráfico o la creación de la Dirección de Investigación y Evaluación de la Carrera Policial (DIECP). También hay que mencionar las medidas para bloquear la señal de la telefonía móvil en los centros penitenciarios con el objeto de evitar no solo las llamadas que tenían como fin la extorsión, sino también combatir la planeación de los crímenes desde las cárceles. Destaca asimismo la Ley de Protección de Espacios Aéreos, o la "ley de derribo de aviones", que establece el protocolo a seguir ante las aeronaves que sean sospechosas de traficar con drogas.

Desde el Ejecutivo, Juan Orlando Hernández ha impulsado más aún el concepto de militarización de la seguridad. Además de la policía militar, puso en marcha en septiembre de 2014 la Tropa de Inteligencia y Grupos de Respuesta Especial de Seguridad, conocidos como los TIGRES, una unidad de élite de 200 efectivos subordinada a la Secretaría de Defensa y adscrita a la policía nacional preventiva, pero independiente de esta, cuya labor principal es la lucha contra el crimen organizado. Con la llamada "Operación

16 La CRSP se puso en marcha en enero de 2012 mediante Decreto Legislativo para diseñar un proceso de reforma integral de la Política de Seguridad, incluyendo medidas para la policía, los fiscales y los jueces. Esta comisión funcionó hasta su disolución en la última sesión del Congreso de la legislatura de Lobo Sosa. CEDOH (2014).

17 El PDCH solo obtuvo un diputado en las elecciones de 2013, pero al inicio de la legislatura de 2014 el diputado José Eduardo Coto, electo por LIBRE, se incorporó al PDCH.

18 Este tema probablemente ocupe parte de la campaña electoral de las elecciones de 2017, porque Hernández envió una iniciativa de decreto legislativo para someter a plebiscito la constitucionalidad de la PMOP.

19 También conocida como "Tasón", la Ley de Seguridad Poblacional aplica entre otros impuestos a las transacciones bancarias con el objetivo de destinar recursos para la prevención y el control de la delincuencia y la criminalidad. 
Morazán", Hernández puso a patrullar en las calles a los efectivos de la Policía Militar y a los TIGRES. Otra de las políticas en materia de seguridad que ha implementado el gobierno es el programa "Guardianes de la Patria", con el que se encomienda a las Fuerzas Armadas la formación de jóvenes con el fin de que no se impliquen en maras, pandillas o con el crimen organizado. La Fuerza de Seguridad Interinstitucional Nacional (FUSINA), integrada por las Fuerzas Armadas, la Policía Nacional, la Dirección de Inteligencia, el Ministerio Público y la Corte Suprema de Justicia, fue creada en enero de 2014, también encargada del combate al crimen y la violencia del país. Igualmente hay que destacar la creación de la Policía Comunitaria en septiembre de 2013, que supone el despliegue de 450 unidades de los barrios de los dieciocho departamentos, o la Fuerza Nacional Antiextorsión (FNA) establecida como una unidad especial de la Policía Nacional para luchar contra la extorsión. Otras medidas que se han puesto en marcha: la ley de limitación del servicio de telefonía móvil, internet y wifi en centros penales, ${ }^{20}$ la prohibición de la venta de bebidas alcohólicas los domingos por la tarde hasta la mañana del lunes, o la recuperación de la seguridad estatal de los aeropuertos, antes de gestión privada.

Esta política de mano dura pone de manifiesto la recuperación del poder que las Fuerzas Armadas habían perdido en las reformas de los años noventa durante el gobierno de Carlos Reina (1994-1998). A estas se les encomienda ahora la política relacionada con la seguridad ciudadana. ${ }^{21}$ Una agenda que no es muy diferente a la que habían puesto en marcha sus predecesores nacionalistas que también dieron preeminencia a la seguridad. ${ }^{22}$ No obstante, el golpe de Estado de 2009 marca un antes y un después no solo por su participación en la ejecución del golpe, sino en la concepción de su papel protagonista como garantes de la seguridad del país.

Pese a todo, no han faltado críticas a esta agenda política centrada en la seguridad, porque los resultados aún no son evidentes, aunque las cifras muestran una ligera disminución de la criminalidad en el último año; no hay un enfoque integral en la lucha contra las causas de la inseguridad y de la violencia, como tampoco se combate la impunidad y el deteriorado sistema de justicia, también graves problemas del país. No en vano Honduras ocupa el séptimo lugar en ranking del Índice Global de Impunidad elaborado por el Centro de Estudios sobre Impunidad y Justicia. ${ }^{23}$ Además, este énfasis ha significado no solo el fortalecimiento institucional de las Fuerzas Armadas y la Policía, sino también el incremento paulatino de los presupuestos en Defensa y Seguridad. Si en 2008 el monto destinado a Defensa era el 3,8\% del presupuesto nacional, siendo el 0,88\% del PIB, en

Decretos 255-2013 y 13-2014, "Reforzado bloqueo de llamadas en cárceles", La Tribuna, 22-4-2014.

Además de Pacheco al frente de la Secretaría de Seguridad y de FUSINA, Hernández ha nombrado como funcionarios a varios militares: el jefe del sistema penitenciario, el jefe de aduanas, el director de aviación civil y los responsables de las agencias de vivienda y servicios sociales. Unas decisiones que no han estado exentas de críticas por el papel que se les está otorgando a las fuerzas armadas en la seguridad interna.

22 Maduro con la "mano dura", "cero tolerancia" y "Honduras segura" puso en marcha la Ley Antimaras, y sacó a los militares a las calles. Por su parte Lobo, con su fracasado Plan de Nación, se proponía reducir la criminalidad a niveles inferiores que el promedio mundial.

23 Fundación Universidad de las Américas, Puebla (2015). 
2015 se destinó 5,12\%, siendo el 1,29\% del $\mathrm{PIB}^{24}$ al tiempo que los presupuestos en el ámbito social, en salud o en educación han sido reducidos o congelados.

Destaca asimismo la Ley de Clasificación de Documentos Públicos aprobada en enero de 2014, que faculta a los organismos públicos a mantener como reservada, confidencial y secreta hasta 25 años información relacionada con la seguridad y la defensa nacional, lo que claramente quebranta la política de transparencia defendida y publicitada con la Ley de Transparencia y Acceso a la Información Pública por el gobierno pero también normativa internacional y preceptos constitucionales. ${ }^{25} \mathrm{~A}$ pesar de las numerosas críticas y peticiones de reforma con el fin de facilitar el trabajo de la recién instalada Misión de Apoyo Contra la Corrupción y la Impunidad en Honduras, la norma sigue vigente.

En el ámbito social, el gobierno nacionalista anunció implementar "una política progresista y justa de protección social", teniendo como objetivo prioritario acabar en cuatro años con el analfabetismo. Sin embargo, hasta la fecha las actuaciones del gobierno más destacadas tienen que ver con la continuación de programas asistenciales puestos en marcha con el gobierno anterior como el "Bono Diez Mil”, que consistía en la transferencia de dinero a las familias con niños en situación de pobreza extrema, o la implementación de otros similares como "Vida Mejor", "Techos Seguros", "Pisos de Cemento", "Crédito Solidario", "Con Chamba Vivís Mejor", que tienen las mismas características al consistir en la asistencia a colectivos vulnerables. En definitiva, una política social focalizada que no supone un enfoque sistémico que ayude a la redistribución de la riqueza, sino más bien son instrumentos que perpetúan las prácticas clientelares y la dependencia del gobierno de turno. Son varias las voces que señalan cómo estas políticas son más bien estrategias de control político, que el gobierno utiliza para atraer votantes y lograr cierta popularidad del Presidente.

\section{PODER LEGISLATIVO: OPOSICIÓN DIVIDIDA Y BAJO RENDIMIENTO}

Las elecciones de 2013 dibujaron un Congreso fragmentado, donde el PNH no obtuvo la mayoría al contar con 48 de los 128 escaños legislativos, frente a los 37 de LIBRE, 27 del PL, 13 de PAC y 3 los minoritarios, PDCH, PINU-SD y PUD. La Cámara tradicionalmente ha servido a los intereses del Poder Ejecutivo mediante la aprobación de legislación y la implementación de políticas públicas, algo que estuvo garantizado con las mayorías del partido de gobierno o con los pactos con los minoritarios. ${ }^{26}$

24 Un informe de la Alianza por la Paz presentado en 2015 señaló que la secretaría de Defensa ha incrementado su presupuesto de $420 \%$, entre 2006 y 2015 (pasando de 1.040.741.000 millones de lempiras a 5.418.882.357), mientras que la Secretaría de Seguridad ha logrado un aumento presupuestario del $112,8 \%$, pasando de 1.817 millones en 2006 a 3,67 millones en 2015.

25 Esta ley fue inicialmente suspendida hasta marzo debido a numerosas críticas y protestas, pero hasta la fecha no se ha reformado.

26 Hasta la legislatura actual, en dos ocasiones el partido ganador de las presidenciales no ha obtenido la mayoría en el Congreso: durante las presidencias de Maduro y Zelaya, en ambos casos el partido gobernante se apoyó en alguno de los minoritarios, PDCH en el primer caso y PUD en el segundo. 
La nueva composición ha ocasionado un papel menos preponderante que en el pasado del Legislativo, en tanto que el Ejecutivo y en particular la Presidencia de la República han aumentado su relevancia. Así las cosas, Hernández tiene a priori menos poder del que tuvo en el período anterior como presidente del Congreso, teniendo en cuenta que son necesarios 65 escaños para contar con mayoría simple, y 86 para la calificada. Por ello, este gobierno se ha visto forzado a buscar apoyos de las otras fuerzas políticas para sacar adelante su agenda legislativa y garantizar la gobernabilidad. Sin embargo, hay algunos elementos que han facilitado su labor en estos dos años de gobierno: por un lado, hay que considerar la gran cantidad de legislación impulsada antes de la toma de posesión del gobierno, lo que ha significado la continuación de su programa político con mínimas variaciones. Además, hay que tener en cuenta el poder e influencia que sobre los diputados tiene el partido gobernante y en particular el presidente del Congreso con la asignación de recursos obtenidos por medio del Fondo de Desarrollo Departamental o de los subsidios con los que los diputados llevan a cabo diferentes actividades en sus departamentos. ${ }^{27}$ Un sistema que reproduce el clientelismo y que impacta en el comportamiento de los diputados y en su disciplina de partido. ${ }^{28}$ Finalmente, la ausencia de un frente común por parte de la oposición. Los dos primeros años de la legislatura han puesto de manifiesto la conformación de alianzas inestables y la existencia de problemas internos en los partidos de oposición que les han impedido una acción conjunta.

En este sentido, el Partido Liberal ha evitado desde el comienzo formalizar una alianza con el PNH, que puede minar sus posibilidades de recuperación frente a su electorado en los comicios de 2017. Son varias las ocasiones en las que la bancada no ha tenido un comportamiento cohesionado en la Cámara y se ha dividido apoyando al partido del gobierno. Por ejemplo, las diferencias entre la directiva del partido y la bancada que se evidenció en la votación para la constitucionalización de la PMOP, en la que 10 diputados votaron con el PNH. No son menores los problemas que acusan los nuevos partidos. LIBRE desde el inicio vio reducida su bancada debido a varias deserciones. Hasta la fecha, ha perdido diez miembros, seis diputados y cuatro suplentes. De ellos uno pasó al $\mathrm{PDCH}$, otros han creado una bancada independiente, o un nuevo movimiento, "Nueva Ruta", y otro ha pasado a engrosar las filas liberales. ${ }^{29}$ Además de los transfuguismos, también ha mostrado conflictos y problemas para acordar una agenda política común.

27 Esto tiene que ver con otro de los rasgos diferenciados del Congreso como es la dinámica localista que desarrollan los diputados, que tienden a focalizarse en las acciones en sus departamentos reemplazando en ocasiones la labor de los alcaldes en la provisión de unos deficientes servicios públicos esenciales. Así, mientras que los Fondos de Desarrollo se crearon para que los diputados realizaran proyectos de desarrollo social en las comunidades y se entrega a ONGs municipios o asociaciones, y siguen una normativa (Reglamento de Aplicación del Fondo de Desarrollo Departamental), los subsidios no tienen una disposición legal similar. Es más, suelen ser asignados a los diputados de manera discrecional por el presidente del Congreso, siendo los pertenecientes a su partido los más beneficiados.

28 Por ejemplo, según un informe presentado por Democracia Sin Fronteras (2016), hasta la legislatura anterior (2010-2014) cada diputado habría recibido 50.000 dólares en concepto de Fondo Social de Planificación Departamental, que tendría como fin la compra de materiales agrícolas, escolares, médicos, reparación de calles, ayuda a la organización de festejos locales, o simples donaciones a las familias necesitadas.

29 El primero fue Eduardo Coto que pasó a la Democracia Cristiana; también abandonó el partido Esdras Amado López que creó su propio movimiento llamado Nueva Ruta. También lo han hecho Omar Rodríguez, Tatiana Canales, Jenny Murillo y Héctor Padilla, que están integrados en la bancada independiente. 
Estas dificultades ya se plantearon desde sus inicios, debido a su diversidad interna al conjugar una lógica social, que emana de las organizaciones del FNRP, y una política, nutrida fundamentalmente de exliberales y que dieron forma a cinco movimientos internos para las primarias de 2012 (Otero Felipe, 2013). En la actualidad se constata por un lado la desvinculación con el FNRP con las consecuencias que puede tener en términos de apoyo de los sectores sociales, pero también la ausencia de un liderazgo aceptado por todos. El surgimiento de varias corrientes de cara a la postulación de candidaturas en los próximos procesos internos pone de manifiesto que el faccionalismo no es una característica única de los partidos tradicionales. ${ }^{30}$

Problemas similares está sufriendo el PAC, que también desde sus inicios afrontaba como desafíos principales la estructuración de un discurso más allá de la lucha contra la corrupción, y la cohesión en torno a un líder necesarios para manejar una inexperta bancada legislativa. En este sentido han sido frecuentes los enfrentamientos entre el liderazgo de Nasralla y los miembros de la bancada que no han seguido la línea del partido en votaciones clave. Todo ello ha provocado cierta incapacidad para articular consensos y conformar estrategias comunes ante los diferentes temas y reformas pendientes, más allá de las dos declaratorias emitidas, una a finales de 2014 y otra a inicios del 2015 acerca de los puntos en común relativos a la reelección presidencial, el reconocimiento del plebiscito y el referéndum, o la necesidad de una nueva ley electoral y de organizaciones políticas, entre otras. ${ }^{31}$

Ante esta situación se observa un PNH mucho más organizado y cohesionado en el legislativo, que ha logrado imponer su dominio al establecer alianzas puntuales con los partidos minoritarios. Hasta la fecha ha contado con la bancada independiente, el diputado de PUD y el PDCH, además de una parte de la bancada liberal de forma ocasional. Esto se ha puesto de manifiesto en diferentes ocasiones en la legislatura, por ejemplo en la conformación de las 29 comisiones permanentes en las que la mayor parte de las presidencias acabaron en manos nacionalistas o liberales frente a la segunda fuerza política, LIBRE. También se observa en la integración de la Directiva del Congreso, cuya dirección recayó en el nacionalista Mauricio Oliva, y que fue pactada por PNH, PLH, PUD, PDC y un diputado de LIBRE (expulsado tras conocerse su apoyo), permitiendo al PNH controlar la presidencia. Esta directiva fue reelegida en diciembre de 2015 sin que nuevamente la oposición pudiera conformar un frente común.

Otra muestra de la influencia del PNH en estos dos años, a pesar de estar en minoría, se ha puesto de manifiesto en el nombramiento de diferentes organismos y funcionarios públicos, otra de las atribuciones relevantes del Congreso. Por ejemplo, la elección del Comisionado Nacional de los Derechos Humanos, Roberto Herrera, fue impulsada por el PNH y apoyada por el PLH y PAC, logrando 83 votos a favor, 30 en contra y

30 Hasta la fecha se han reconocido hasta diez movimientos internos que comienzan a organizarse de cara a los procesos de marzo del 2017. "Cisma en LIBRE por intento de 'golpe' a Manuel Zelaya”, Tiempo, 23-9-2015; "Diez movimientos afloran en Libre", La Tribuna 26-10-2015.

31 Véase el Acuerdo-pronunciamiento de cuatro partidos políticos en defensa del pueblo y la democracia. Tegucigalpa, 24 de febrero de 2015. 
5 abstenciones. En la misma línea la elección de los nuevos magistrados del Tribunal Supremo Electoral, realizada antes de la toma de posesión del actual Congreso, fue pactada por una fracción del PLH como parte de las negociaciones para conformar la Junta Directiva del nuevo Congreso. Esto tampoco ha supuesto grandes cambios en el reparto de la tradicional "cuota" al quedar ratificados dos de los magistrados (uno nacionalista y otro del PDCH) y ser elegidos otro nacionalista y otro liberal. ${ }^{32}$

La elección de los miembros de la Corte Suprema de Justicia es otro ejemplo significativo. En el pasado la correlación de fuerzas estaba más equilibrada, "repartiéndose" sin problema los magistrados, 8 para un partido y 7 para el otro, negociando el presidente de la Corte. En esta ocasión la elección ha sido un poco más compleja, pero el resultado ha sido semejante. El nombramiento comenzó en agosto de 2015 con la elección de la Junta Nominadora que debía proponer los candidatos al Congreso. ${ }^{33}$ Una Junta que fue bastante cuestionada, tanto en su papel como en sus lealtades y resultados, pues durante su proceso de selección hubo varias acusaciones del intento de influencia de Hernández y muchas críticas por los nexos de los candidatos propuestos con los dos partidos tradicionales. La Junta presentó en enero de 2016 los 45 candidatos al Congreso, tras varias semanas de preselección, de los que 15 debían ser elegidos por mayoría calificada. Dicha mayoría no se alcanzó en la primera votación, por lo que se votó individualmente a cada candidato de manera secreta, logrando acuerdo para 8 de los 15 magistrados (tres abiertamente liberales y cinco nacionalistas) con los votos a favor del PNH, PDCH, PUD, PLH y tres diputados de LIBRE. ${ }^{34}$ La elección se completó en la sexta votación en febrero, contando con los votos del oficialismo, además de los del PLH, PDCH dos de LIBRE y dos del PAC, de este modo se eligió una CSJ donde ocho de los magistrados son allegados al nacionalismo y siete al liberalismo.

En definitiva, aunque podía esperarse que la mayor fragmentación y polarización en el Congreso llevara a una mayor inestabilidad o conflicto, lo cierto es que el nacionalismo ha encontrado una oposición dividida y ha podido sacar adelante estos nombramientos. Sí parece, en cambio, que esta conformación ha impactado en la productividad del Congreso en el primer período, que suele ser el de mayor actividad legislativa y estos meses ha evidenciado un menor rendimiento. Por ejemplo, en el primer período legislativo (enero 2014- enero 2015) se presentaron 755 proyectos de ley y 99 mociones; de ellas 167 fueron presentadas por el Poder Ejecutivo y 7 por el Poder Judicial. Unas cifras que son ligeramente más bajas a las correspondientes de la legislatura anterior, ${ }^{35}$ pero que

32 Los magistrados que regirán el órgano hasta el 2019 se eligieron en enero antes de finalizar la legislatura anterior, meses antes de que terminara el mandato de los magistrados salientes.

33 La Junta se integró por 14 representantes, siete propietarios y siete suplentes. En ella había personalidades de la Corte Suprema de Justicia, el Colegio de Abogados de Honduras, el Comisionado Nacional de los Derechos Humanos, el Consejo Hondureño de la Empresa Privada, Claustro de Profesores de las Facultades o Escuelas de Ciencias Jurídicas, organizaciones de la Sociedad Civil y las Confederaciones Obreras.

34 Se lograron 82 votos: 26 votos del PLH, 3 del PDCH, 1 de PUD, 3 de los diputados que renunciaron a LIBRE, y 49 del oficialismo. Los votos en contra fueron 29 de LIBRE, 13 del PAC, 1 del PLH y 1 del PINU-SD. Las dos abstenciones fueron del partido LIBRE. 
no parecen ser problema para un ejecutivo que está sorteando con gran habilidad un escenario legislativo adverso.

\section{CONCLUSIONES}

Las páginas anteriores han mostrado que Honduras sigue enfrentando un estancamiento en su desarrollo democrático. ${ }^{36}$ Entre los problemas que persisten se encuentran el acelerado deterioro de las instituciones, la falta de confianza en las mismas, a lo que no ayuda su politización partidaria, y los escándalos de corrupción. A esto se suma la permanente situación de violencia, que ha generado un mayor protagonismo de las Fuerzas Armadas en la política de seguridad, y su participación en diferentes esferas públicas.

Honduras continúa siendo una economía débil, aunque en 2015 se mejoró ligeramente en algunos indicadores. A pesar de que el gobierno ha tomado algunas medidas necesarias en cuanto al manejo macroeconómico, el país sigue enfrentando una situación muy difícil debido a la gran proporción de personas en situación de pobreza y el alto nivel de desigualdad del ingreso. Aunque los programas sociales focalizados pueden tener cierto impacto en un sector de la población, no dejan de ser mecanismos de control político. Sigue faltando una visión más a largo plazo que incida en las causas de ambos problemas. A esta situación se aúnan los recortes en el gasto público programados en el acuerdo firmado por el gobierno hondureño con el FMI, los que pueden repercutir en el deterioro del nivel de vida de los más pobres. Si el país no logra crear opciones viables para que estas personas mejoren su situación, como empleos estables y bien remunerados, y servicios de salud y educativos de calidad, el grave problema de la inseguridad no podrá ser resuelto de manera efectiva.

En el ámbito político los retos no son menores. Los resultados de las elecciones de 2013 confirmaron el proceso de reconfiguración en el sistema de partidos que se anticipaba tras el golpe de Estado. La crisis de representación del sistema y el descrédito de la política tradicional ayudaron a que los nuevos partidos entraran con éxito en el sistema. No obstante, hay señales que advierten de las dificultades en la consolidación de LIBRE y PAC y por extensión a las formaciones en ciernes. Por un lado, como se ha señalado, no están haciendo una oposición efectiva. Ambos están sufriendo problemas de faccionalismo y liderazgo muy similares a los que hacen frente los partidos tradicionales, pero con el agravante de que no han tenido tiempo ni los recursos necesarios para consolidar su estructura territorial ni social como lo han hecho el PLH y PNH a lo largo de décadas. Por otro, en un país donde las identidades partidistas fueron tan relevantes, no parece que hayan forjado en estos años una identidad o simpatía partidista. Según revela la encuesta realizada por CESPAD (2015b), las identidades partidistas siguen siendo mayoritarias a los partidos tradicionales: $37 \%$ se identifica con el $\mathrm{PNH}, 23 \%$ con el $\mathrm{PLH}$, mientras que $19 \%$ y $13 \%$ declararon identificarse con LIBRE y PAC respectivamente. Tampoco 
parece que haya mucho cambio en la intención de voto: $28 \%$ de los encuestados votaría al PNH, 15\% al PLH que parece recuperarse de su crisis interna, en tanto que a LIBRE lo votaría $13 \%$, al PAC $7 \%$ y $28 \%$ no tendría decidido su voto.

Es evidente que estamos ante una nueva realidad partidista y las próximas elecciones serán clave para determinar su formato. Hay varios elementos que prevén una nueva victoria nacionalista, y la posibilidad de que se permita la reelección lo hace más probable, debido a la favorable valoración de la gestión de Juan Orlando Hernández (CESPAD 2015). Hernández demostró una gran habilidad para avanzar su agenda de gobierno antes de tomar posesión como Presidente, ahorrando al partido (y a él mismo) las difíciles negociaciones en un Congreso fragmentado. La presencia de nuevas fuerzas políticas en el Legislativo, si bien ha ocasionado una mecánica diferente, no ha supuesto un gran cambio en las políticas públicas del gobierno precedente ni en el control de instituciones clave como la CSJ o el TSE en esta primera mitad de la legislatura. Hasta ahora y pese al nuevo escenario los dos partidos tradicionales, especialmente el Nacional, siguen manejando los resortes del poder, lo que hace pensar que nos encontramos en un escenario lampedusiano, en el que todo cambia para que todo siga igual.

\section{REFERENCIAS}

Ajenjo Fresno, Natalia. 2001. "Honduras". En Partidos Políticos en América Latina: Centroamérica, México y República Dominicana, editado por Manuel Alcántara y Flavia Freidenberg. Salamanca: Ediciones Universidad de Salamanca, 179-278.

2007. "Honduras: nuevo gobierno liberal con la misma agenda política". Revista de Ciencia Política 27 (1): 165-181.

Alcántara, Manuel. Proyecto de investigación "Elites Parlamentarias de América Latina" (PELA). Salamanca, Universidad de Salamanca, 1996-2014.

Centro de Documentación de Honduras, CEDOH. 2014. "Seguridad y Política Anticorrupción en Honduras". Boletín 99. Tegucigalpa: CEDOH.

Centro de Estudios para la Democracia (CESPAD). 2015a. Análisis de Coyuntura de Honduras, diciembre. Tegucigalpa: CESPAD.

. 2015b. "Encuesta de opinión pública". En: http:/ / cespad.org/sites/default/files/Encuesta\%20 presentacion\%20version\%20final.pdf.

Fundación Democracia sin Fronteras (FDSF). 2016. Informe de Producción Legislativa y Manejo de Recursos Públicos. En: http://www.fdsf.hn/index.php/component/content/frontpage/ frontpage.html?start=5.

Fundación Universidad de las Américas Puebla. 2015. Índice Global de Impunidad. En: http:/ / udlap. $\mathrm{mx} /$ cesij/files/IGI_2015_digital.pdf.

Freedom House. 2015. "Freedom in the world. 2015". En: https:/ / freedomhouse.org/.

Johnston, Jake y Lefebvre, Stephan. 2013. Honduras Since the Coup: Economic and Social Outcomes. Washington, D.C.: Center for Economic and Policy Research. En: https:/ / cepr.net/.

Lefebvre, Stephan. 2015. Honduras: IMF Austerity, Macroeconomic Policy, and Foreign Investment. Washington, D.C.: Center for Economic and Policy Research. En: https:/ / cepr.net/.

Moreno, Ismael. 2015. "Ascenso y caída del clan de los Rosenthal". Revista Envío, 404. En: http:/ /www. envio.org.ni/.

Observatorio de la Violencia del Instituto Universitario en Democracia, Paz y Seguridad (Iudpas). 2016. Boletín anual sobre Mortalidad y Otros 40. En: www.iudpas.org/. 
Otero Felipe, Patricia. 2013. “El sistema de partidos de Honduras tras la crisis política del 2009: ¿el fin del bipartidismo?". Colombia Internacional 79:249-287.

. 2014. "The 2013 Honduran General Election". Electoral Studies 35: 398-402.

Romero Iglesias, Edilberto. 2015. "El manejo político de la seguridad en la transición al nuevo gobierno". En El manejo político de la inseguridad pública: Tendencias, peligros e impacto, editado por Víctor Meza. Tegucigalpa: Centro de Documentación de Honduras, 75-92.

Ruiz Rodríguez, Leticia y Otero Felipe, Patricia. 2013. Indicadores de partidos y sistemas de partidos. Madrid: Centro de Investigaciones Sociológicas.

Sosa, Eugenio. 2014. "Honduras: Entre criminalidad, enfrentamiento mediático, protesta social y resultados electorales cuestionados". Revista de Ciencia Política 34 (1): 203-2019.

Spring, Karen. 2013. "Context of the Honduran Electoral Process 2012-2013: Incomplete List of Killings and Armed Attacks Related to Political Campaigning in Honduras". En: http:/ /rightsaction.org/.

Taylor, Michael y Herman, V.M. 1971. "Party Systems and Government Stability". American Political Science Review 65 (1): 28-37.

\section{Prensa:}

Criterio

El Heraldo

La Gaceta

La Prensa

Tiempo

Patricia Otero Felipe es doctora en Ciencia Política por la Universidad de Salamanca y profesora e investigadora en el Área de Ciencia Política de la Universidad de Burgos. E-mail: potero@ubu.es.

Juan Antonio Rodríguez Zepeda es estudiante del doctorado en Estado de Derecho y Gobernanza Global en la Universidad de Salamanca y profesor asociado en el Área de Ciencia Política de la Universidad de Burgos. E-mail: jarz@usal.es. 
